\title{
An Animal - Many Persons? Animal Personhood in Face of the Modularity of Mind
}

\author{
Uta Maria Jürgens ${ }^{1,2}$ \\ ${ }^{1}$ Swiss Federal Institute of Technology Zürich ETHZ, Department of Environmental Systems Science, CH-8092 Zürich, \\ Switzerland. \\ ${ }^{2}$ Swiss Federal Research Institute WSL, Social Sciences in Landscape Research Group, CH-8903 Birmensdorf, \\ Switzerland.
}

Correspondence: Uta Maria Jürgens, Swiss Federal Institute of Technology Zürich ETHZ, Department of Environmental Systems Science, CH-8092 Zürich, Switzerland.

Received: July 5, 2016

doi:10.11114/ijsss.v4i9.1754
Accepted: July 18, 2016

Available online: July 20, 2016

URL: http://dx.doi.org/10.11114/ijsss.v4i9.1754

\begin{abstract}
This essay analyzes how the Modularity of Mind impacts the anthrozoological argument that non-human animals are persons. Comparative research on human and animal minds suggests that human and other-than-human minds differ in their mental architecture such that animal cognition is largely modular whereas human thought fluidly integrates contents across modules. If animal minds are modular, then the idea of non-human personhood is challenged. Specifically, an animal with a modularized mind would not be one person facing the world and reflecting on itself in an integral manner, but would be an individual made of many persons: The animal would experience one reality and one self pertaining to each module (or partly-integrated domain of thought) and thus "be" one distinct person in each of these worlds. Yet, within the framework of human-animal encounters, animal personhood can be meaningfully construed despite modularity of animal minds. On this account, animal personhood is conceived by virtue of the human ability to meta-integrate mental contents: The human mind meta-integrates the animal mind's modularized experience for the animal. Thus, in human-animal interactions, humans face the animal as a functional whole, as an integral animal person.
\end{abstract}

Keywords: modularity of mind, cognitive fluidity, non-human personhood, subjectivity, respective realities

\section{Introduction}

Here is a challenge for the anthrozoological community: animal personhood is a construction of the human mind. With this claim, I'm far from betraying the efforts of ingenious scholars of disciplines as varied as philosophy, psychology, ethology, sociology, anthropology, history of religion, politics, law and many others who have joined intellectual forces to establish animal personhood as the essential center-piece for providing the scientific, conceptual and political ground of a new human-animal relationship. Neither am I recanting my own attempts to assist this rethinking and restructuring (Jürgens, 2014; 2016). To the contrary, in this paper, I am raising a problem that no one who is interested in conceptually grounding the notion of non-human personhood (indeed: personhood tout court) should ignore. And I'm offering a solution.

Animal, or more general, non-human personhood is an essentialist-cum-moral notion proposing that animals can (some say: should) be considered as unique individuals, exhibiting agency, being endowed with subjectivity, and an internal value just like humans. Thus, the idea of personhood is pivotal for "reshaping" the moral status of animals since it "identifies a category of morally considerable beings" (Gruen, 2010). By endowing non-humans with the attribute of personhood, anthrozoology seeks to overcome the Western classification assigning humans and animals to different ontological - and hence: moral - realms. Mental architecture has played a critical role in drawing the line between humans and animals. Accordingly, animal personhood advocates bring arguments that rely on scientific evidence about animals' complex minds to the forefront in order to erase or at least push that line further down the genealogical tree (Brown, 2015). Mental capacities of animals have been considered within the range of sentience, the being's ability to experience pain, pleasure and similar basal psychophysical states, to intelligent cognition and behavior such as future planning or understanding the mental states of others. My intention is not to participate in the meticulous debate over 
animals' mental capacities. We do have sufficient evidence to state that animal minds are far from being the behaviorists' black boxes whose content either cannot be validly accessed - or which are empty altogether. Multiple studies attest to animals' ingenious built-in toolkits, deliberate cunning, and emotional endowments exhibited both in the laboratory and in real-life circumstances (e.g. Bartal, Decety, \& Mason, 2011; Bekoff, 2007; Bentley-Condit \& Smith, 2010; Connor \& Mann, 2006; Dally, Emery, \& Clayton, 2010; Gallistel, 2000; Janik, Sayigh, \& Wells, 2006; Penn \& Povinelli, 2007; Premack \& Woodruff, 1978; Shettleworth, 2001, 2009). Moreover, not only research scientists but most persons who have ever lived or worked with animals can testify that animals exhibit the destinct characteristics of individual beings (Brown, 2015; A. M. Gentner, 2016; Ogden, 2012).

There are passionate debates over how animals' abilities are internally realized, over whether and how these abilities are experientially accessible to them, and over the details of what these abilities mean in comparison to respective human behavior. However, there simply can be no serious question any more about whether or not animals are individuals with complex minds of their respective kinds. While empirical studies cannot ultimately decide on the transspecific "other mind problem" (Harnad, 2016; Shettleworth, 2009), i.e., the question of whether and to what extent animals are conscious, I have developed the concept of "respective realities" as a way of thinking about animal subjectivity. Every animal species, in fact, every human or animal individual is thought of as having his or her unique access to the one outside world, and I hold that these accesses are equally valid. Thus, I am firmly committed to the view that despite all obvious differences between human and non-human animals, and between non-human animals of the various species, all their respective "minds" are perfectly nested within the one world which we all inhabit and which we perceive in our respectively different ways (Juergens, under review; manuscript available upon request).

My concern, thus, is not with animal personhood when "personhood" is being understood as the sum of the parts forming the psychic life with which animal individuals are endowed. What I am concerned with (and actually, about) is whether there is a whole integrating the psychic parts. In other words: How can we conceive of a given animal individual as an integral "person" who can be a partner in human-animal encounters?

\section{The Challenge: Modularized Minds}

The complexities with conceiving animals as persons in regard to mental architecture hinges on the so-called modularity of mind (Fodor, 1983). Modules can be understood to be compartments of the mind each concerned with a specific mental process and content. The differences between different accounts of modularity (e.g. Robbins, 2010; Wilson, 2008), although conceptually important, need not concern us for the purpose of the present paper. It suffices to assume that modules are functional units, independently processing and producing information for further computation within subsequent modularized or centralized processes. I take for granted that the synthesis of cognitive, developmental, and evolutionary psychology, archeology, neuropsychology, and ethology has firmly established that at least, the input-systems, such as the faculties of the perceptual system, of animal and human minds function in a modularized manner. Moreover, there are a number of operations in subsequent "higher-order" processing in human and other-than-human minds which are good candidates for modules, too (e.g. Gallistel, 2000; Mausfeld, 2005, 2008; Mishkin, Ungerleider, \& Macko, 1983; Mithen, 1996; Samuels, 2000; Shettleworth, 2012; Spelke \& Lee, 2012). This account construes the mind as being structured by modules nested within modules, i.e., as a hierarchy of processes occupied with processing and producing domain-specific contents, and working independently from each other as well as from any conscious pondering (a characteristic known as "informational encapsulation", Fodor, 1983). One module's output (or several modules' outputs) provide(s) the input for modules on the next level of the processing hierarchy. Thus when the production of information flows vertically through a mind, there is increased integration, allowing for "concepts of concepts" (Sperber, 1994) to be formed as higher-order mechanism operate on outputs of several lowerorder modules. If this premise is correct, then our and other animals' conscious mental lives are constituted by the final output of the highest-order faculties.

The second key premise is that the human mind is special with regard to the homogeneity of its conscious mental life, i.e., its cognitive fluidity (Karmiloff-Smith, 1994; Mithen, 1996). Cognitive fluidity is an essential feature of the human mind and is constituted by an uninhibited flow of ideas across cognitive domains as apparent in e.g. language, art, science and religion. Cognitive fluidity allows for flexible behavior, the use of analogy and metaphor, multiperspectivity (Mausfeld, 2008) and other uniquely human traits unparalleled in the animal realm. This ability is incongruent with modular functioning of conscious cognition, and implies that either modularity is completely absent from the processing in human central systems (Fodor, 1983), or has been overcome as the highest-order modules became permeable in human phylogeny and ontogeny (Mithen, 1996). Either way, the integrate functioning of the human mind bespeaks its cognitive system's architecture: It must be one that allows for "meta-integration" of module outputs. Meta-integration, for the present purpose, might be defined as the final step of integration which occurs when two or more data-formats, or pieces of information, emanating from different modules, feed into one integral stream of experience. While this homogenous consciousness is what corresponds to human cognitive fluidity, animal cognition 
seems to be scarcely equipped with the means to provide meta-integration of representations (Shettleworth, 2009, 2012). Of course, it is not adequate to lump together millions of species under the heading of "animals" and sweepingly talk about "their minds". Millions of species mean an equally diverse number of respective minds with respectively different architectures. Accordingly, my statements about "animals" should be read to imply a graded validity (Chan, 2011). Yet, as researchers of ape cognition and palaeoanthropologists have concurrently and conclusively argued (Boesch \& Tomasello, 1998; Gabora, 2007; Mithen, 1996; Tattersall, 1998), even our closest living and extinct relatives, chimpanzees and early humans, (and allegedly analogously clever animals such as corvids) lack the meta-integration of information which allows for the cognitive fluidity so blatantly characteristic of human thought and culture.

Why is modularity of animal minds a challenge to animal personhood? It is a challenge because the notion of personhood implies that there is one integral whole person.

If minds are modularized, however, there is not one, but there are many persons on the non-human end of a humananimal encounter. It probably constitutes the most inconspicuous and thus most pervasive anthropomorphism to assume that other animals' minds, and hence: experience of the outside and inside worlds, appear as homogenous wholes to animals just like our minds appear to us. We seem to assume that animals' minds are less vividly populated versions of our own minds, with the difference being a gradual one of quantity rather than quality.

Let us switch to a phenomenological stance for the moment of a (quite literal) "thought experiment" in order to see what the presence of meta-representations in human, but not in animal minds implies for the question of animal experience, animal personhood and human-animal encounters. By switching to the phenomenological mode, the things we have technically termed "mental architecture", i.e. minds analyzed "from without", turn into "minds of within" (Nagel, 2012): This view from within reveals the respective lifeworlds (Husserl, 2012), the respective realities of humans and animals (Jürgens, under review).

We may for analytical purposes artificially distinguish two realms of a being's lifeworld: the reality "out there" phenomenally constituting the world independent from the self, and the internal reality as accessible through introspection. Both sides of the phenomenal coin are impacted by modularity of minds; let us consider them in turn.

We are well aware of our human experience of the outside realm: There is a "whole diversity" of things phenomenally lying external to ourselves and constituting the world. This world's axiomatic presence in our subjectivity leaves no doubt - phenomenologically speaking - of its integrity and cohesion. We, the subjects, are firmly positioned within our world and stand in relations to other integrated subjects and objects that figure in it.

This human phenomenal reality as a monolithic whole corresponds to our meta-representation of different facets of the world. Even though these facets are the ultimate result of the modularized processes of perception (Fodor, 1983), the architecture of the perceptual system itself provides for the successive integration of perceptual data formats. For example, material qualities of perceptual objects such as surface shape and color are processed by the perceptual system to yield meaningful object properties such as edibility (Mausfeld, 2010); location and identity of an object are merged for us to see "what" lies "where" (Mishkin et al., 1983); and the sight and the sound of things are joined into, e.g. the perceptual entity of a barking dog. But "mapping across domains" (Carey \& Spelke, 1994) starts to run rampant once these already complex outputs of the perceptual system enter the cognitive level. There virtually is no limit to which concepts we may fuse, merge and join. We may imagine the perfect spaceship a barking dog may devise to harvest goodies grown in the heavens. We may conceive of the analogy that for a dog, devoted barking is structurally similar to a bard pouring his heart into a song. We may begin to scientifically analyze a phonograph of the dog's barking in order to detect patterns possibly corresponding to morsels of dog grammar. In other words, there is no limit to human thought when it comes to creatively combining and recombining concepts.

In contrast, when a mind is modularized, flexible use of concepts is restricted to those domains of which these concepts are natural parts. Dogs may be either barking ferociously or happily; goodies are there to be eaten; spaceships could not be thought of at all (since this would require technical expertise merging thoughts about material qualities with thought about airborne navigation). There would be no metaphors or analogies, as by their very nature, these ideas require a structural similarity between ontologically different entities being recognized and transferred from one semantic context to the other (Gentner, 1988). How may such modularized minds look "from within"'?

Granted, we will never know what it is really like for a bat to be a bat (Nagel, 1974) - or even what it is like for another human to be that someone: We face the "other mind problem" (Harnad, 2016). At best, we can make piecemeal inferences from, e.g. a paramecium's stimulus-reaction pattern to how its innenwelt is constructed like the ingenious Jakob von Uexküll (1909) attempted to do. However, when the task at hand is "just" to compare a non-modularized mind to a modularized mind, we are able to make one point about which we can be sure: that the life-world of a being with a modularized mind is actually many lifeworlds. If animals' minds are largely modular and lack pervasive metaintegration of module outputs, we can at least say that animals' respective realities are heterogenous, compartmentalized, 
indeed, that there is one reality respective to every modularized category of thought (cf. Mithen, 1996). Every module, which processes one aspect of our reality (e.g. movement, color, others' minds, etc.), essentially holds within itself one distinct representation of "world". These "worlds" are computationally independent of each other, and are phenomenally not integrated across modules unless an animal's mental architecture is endowed with a metarepresenting device for merging these world-parts into one phenomenal world.

Of course this view is schematic, as there are many forms of mental architecture ranging between complete modularization (as we may find in "lower" animals such as paramecium) and virtually complete integration of module outputs as in humans. We can be sure that the more similar animals' minds are to ours, the more they tend to have architectures exhibiting partial integration of modules' outputs. Still, if the modularity thesis is true, we must acknowledge the fact that in addition to every animal having his or her respective reality, for each module of an animal's mind that remains informationally encapsulated, there exists one module-bound world nested within that reality.

We have yet to look at the second realm of the lifeworld: the phenomenal inside-view of minds when they contemplate themselves. If it is true that much of mental processes are modular, and if mental architectures differ such that humans, but not animals are endowed with the capacity to meta-integrate concepts and thus exhibit full cognitive fluidity, then a human, but not an animal, can perceive herself as one integral person. If modules are informationally encapsulated and their outputs are not integrated across cognitive domains, animal subjectivity may only provide distinct animal "selves" pertaining to each of these modules, corresponding to the different "worlds" respective to each such module.

Summing up our phenomenal consideration of inner and outer lifeworld realms, an animal individual would actually not be a person living within his or her lifeworld, but would be module-wise persons living in their corresponding lifeworlds. When facing animals, we face a "multiple-other-minds-problem" (Harnad, personal communication). Again, I do assume that animals such as those with which we intentionally interact, dogs, birds, horses, etc. do possess at least partial integration of their cognitive modules and hence have some meta-representations available that are similar to ours. What I am questioning, however, is whether these animals perceive themselves as beings with one perspective visa-vis one world - as we do owing to our cognitive fluidity.

\section{The Solution: Merged Minds}

Before we turn to analyzing the profound implications of animals' modularity of mind for the possibility of meaningful human-animal interactions, let me pause to restate what I do not question.

I argue that the possibility that animals' minds are modular, lack meta-integration of module outputs and hence, cognitive fluidity, impacts on our understanding of the quality of animal subjectivity. Critically however, modularity of animal minds does not preclude the existence of animal subjectivity. Animals may experience subjective states: be sentient or even conscious. The ideas laid out here are neutral as to the question of whether and how animal subjectivity is constituted. But if there is an argument for animal subjectivity, then it is safe to say that modularity is not in its way. Modularity just suggests that there is not one monolithic animal subjectivity, i.e. no integrated stream of consciousness as we humans experience. Instead, there may be module-wise animal subjectivities, in the plural, i.e. one subjectivity for each module. In other words, the possibility of animal minds being modularized and hence, of their being not one person but many persons, allows the animal to have subjective experiences pertaining to to each of these persons.

How, then, can we make sense of animal personhood? Adopting a relational perspective provides the key, i.e. looking at interactions or "encounters" (Jürgens, 2016), between humans and animals rather than just focusing on "the animal" and on its intrinsic properties in isolation. A relational perspective is, I think, inherent in virtually all approaches to establishing animal personhood, which seem to admittedly or implicitly recognize that we may relate to animals as we relate to other humans. At the heart of objective and robust scientific scholarship thus often lies an ideal reminiscent of Thomas Berry's "communion of subjects" (Berry, 1999, p. 82).

An anthrozoological communion presupposes meaningful human-animal encounters. Essentially, human-animal encounters are literally meaningful, constituted when mutually significant information flows between the human's and the animal's minds, i.e. when their minds "merge" such that their respective subjectivities become intersubjectivity. In order for intersubjectivity to emerge, two related requirements must be met: The same elements of the outside world need to be represented in two beings' respective lifeworlds in ways specific to these beings. Specifically, the beings need to be able to represent each others' presence and to put themselves in a relation to the others' presence. If these requirements are met, the two beings can respond to each other's interactive intentions and their mere concomitance becomes coexistence. It is not required for the animal to think human-like thoughts like "I see there is a member of the human species attempting to feed me - that's nice, I'll go make friends with her." It suffices for the animal to understand that "there is something which indicates the need to flee" or even just "there is something" evoking an unconscious flight response. The more elaborate the animal's mental architecture in terms of meta-integration of module outputs, the 
more complex the exchange of information, the more integrated the animal's personhood, and the more holistic its representation of the human person becomes. On the other end of the continuum, there may be animals who cannot meaningfully encounter humans at all if their mind is completely modular and if their respective realities don't overlap at all with humans'. A bee, for example, may not be able to even represent a human's presence, even if, say, the human sniffs at the same flower from which the bee harvests nectar. Unless the human moves incautiously and causes a flight response in the bee, there will be no representation of her in any of the bee's module-wise respective realities. Still, a bee might be considered a person.

The relational perspective which focuses on a potential flow of meaning between the human and animal minds is pivotal for showing how modularity of animal minds does not preclude encountering an animal individual as a person, even if owing to its mental architecture, it is many persons. Based on the "merging minds" metaphor (Jürgens, under review), there are two ways of constituting animal personhood despite the modularity of animal minds, corresponding to two modes of communication between humans and animals.

First, human and animal can communicate module-wise. If both the human and the animal possess a given module $\mathrm{M}_{*}$, in functionally analogous versions $\mathrm{M}_{\mathrm{h}}$ and $\mathrm{M}_{\mathrm{a}}$, respectively, they may be able to exchange information that is specific to $\mathrm{M}_{*}$ 's domain. While human mental architecture allows $\mathrm{M}_{\mathrm{h}}$ 's output to feed into an integral stream of consciousness, it is possible for the human to deliberately focus on that domain-specific information provided by $\mathrm{M}_{\mathrm{h}}$. Assuming that the animal has a minimum of subjectivity in which $\mathrm{M}_{\mathrm{a}}$ 's outputs become-represented, and if it can understand information pertaining to $\mathbf{M}_{*}$ sent by the human, then, module-wise understanding of human and animal are possible. Likewise, the animal's subjectivity inherent in $\mathbf{M}_{\mathrm{a}}$, which in the human-animal interaction "responds" to the human's subjectivity, constitutes the animal's module-specific personhood: Within the respective reality pertaining to $\mathbf{M}_{\mathrm{a}}$, the animal is a subjective agent capable of representing the human's presence and the $\mathbf{M}_{*}$-specific interactive intentions emanating from her. Note that for this $\mathrm{M}_{*}$-bound interaction, it is neither necessary for the animal to understand that the human possesses $\mathrm{M}_{\mathrm{h}}$, nor to represent the human as an integral being inhabiting an integral outside world. All that is required is

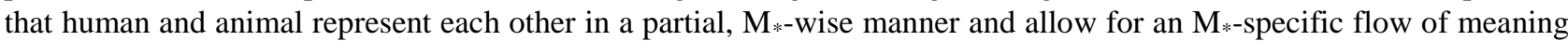
between their respective minds.

The second way of constituting animal personhood is, in fact, a way of constructing animal personhood. What animal minds lack in meta-integration, human minds display in abundance. It seems that humans are hardly able to isolate the information emanating from their different modules. Hence our natural tendency to view other being's minds as integrated wholes - a tendency I have called the "most inconspicious anthropomorphism" above. But is this tendency necessarily a fallacy? After all, even though their mental architecture makes them experience themselves and the outside world in a module-wise manner, animal individuals behave in a homogenous way. Their respective realities are so smoothly dovetailed that they function as integrated entities towards the outside world and as a result, we, as outside observers, perceive them to be wholes. In other words: Animal minds constitute integrated wholes who just cannot represent this wholeness to themselves. When we communicate with animals and (mis)represent their inner worlds as a homogenous stream of experience, what we actually do is meta-integrate their respective realities for them. Animals might lack complete cognitive fluidity, but in human-animal encounters, that is no problem: We, the human end of the interaction, are capable (and in fact: committed by virtue of our minds' holistic architecture) to meta-integrate the domain-specific outputs of the animal mind's modules when we represent this information in our respective reality. This way, even the bee, whose respective realities presumably don't overlap with the human's, but whom we perceive as a fascinating functional whole may be endowed with bee personhood.

But isn't this a fraudulent confusion of epistemology and ontology? If modularity of animal minds is real, then, after all, animal minds are not integrated wholes, they just appear to be. There are two answers to this scepticist conundrum. A pragmatic answer just says: Thinking about animal minds as integrated wholes and, hence, about animals as equal partners in human-animal encounters, works and makes sense to us (cf. Jürgens, 2016); therefore we need not worry about its realness. Possibly, this conception of animal minds has been a critically useful way of thinking for early human survival, as animist heuristics may have helped our ancestors to skillfully predict animal behavior and to hunt successfully (Mithen, 1996).

Then, there is a realist answer to the question of whether a meta-integration of an animal's module-wise realities by and in a human mind might count as valid meta-integration. Granted, if meta-integration of module-outputs occurs by and in the human mind, this makes no phenomenal or epistemological difference to the animal. Specifically, a human's integration of an animal's module-wise respective realities does not cause the animal to experience one homogenous reality. This "vicarious" meta-integration only helps the human to address the animal as if it experienced one homogenous lifeworld. Still, meta-integration of the animal modules' output does occur in real terms. Meta-integration, as defined above, is what happens when two or more data-formats, or pieces of information, originating in different lower-order modules, are fused to form a qualitatively new trans-modular meta-format of this information. This is 
exactly what happens when a human perceives an animal as a homogenous entity, monolithically responding to her interactive intentions. The human perceives the (observable and hence interactionally relevant) outputs of the animal's mental modules and maps them onto integral higher-order data-formats, hence: meta-integrates them. The fact that this meta-integration occurs "in the wrong mind" is negligible for the purpose of creating a meaningful human-animal encounter. If meaningful human-animal-encounters are constituted by the meeting and "merging" of a human and an animal mind such that a flow of information may occur between them, then it is irrelevant, where the interface is located - as long as there is such an interface at some point along the continuum of the merged minds.

This is why, for construing animal personhood despite modularity of animal minds, the explicit focus on human-animal encounters is essential. In and through human-animal encounters, animals are integral persons since we make them entities. Then, animal personhood is no fictitious notion, but a real thing, even though - and because - it is constructed by our human minds.

Accordingly, even if humans and animals may be distinguished by a modularized versus meta-integrated mental architecture, in human-animal encounters the smooth flow of information makes them two end-poles of a mind-made continuum. Akin to Clark and Chalmer's (1998) notion of an "extended mind", human-animal encounters may technically be understood as an anthrozoological coupled system. In other words, our human integral personhood is intrinsically provided by virtue of our meta-integrating cognitive architecture, and we also construe the animal's personhood by virtue of the same mechanism. Hence, the human and the animal facets of personhood are respective sides of the same coin, they cannot straightforwardly be segregated into a person, the human, and a non-person, the animal. When human and animal minds merge, animals are persons.

\section{Conclusions}

There are many ways for conceiving of animal personhood (Anderson, 2004; Gruen, 2010; Stucki, 2015) that hold in addition to the argument presented here. I have been attempting to show in this discussion that what, at first glance, looks like a serious obstacle to construing animal personhood, i.e. the modularity of animal minds and hence the category-bound experience of their respective realities and of themselves, is, in fact, a challenge for thinking more thoroughly about this notion and for carefully substantiating it. If empirical findings will show that animal minds are not modular to the extent assumed here, or exhibit meta-integration of information to an extent that plausibly constitutes them as integral persons with a homogenous respective reality - then I shall be the first one to happily reject the concerns that motivated this inquiry. Until, however, such evidence will be brought forth, we anthrozoologists need to be prepared to answer to objections raised against animal personhood that are based on the modularity of animal minds. This essay contributes to this answer by showing how animal personhood may meaningfully be constituted within the framework of human-animal encounters.

\section{Acknowledgments}

I'm indebted to Dr. Jessica Schwarzenbach for her thorough proof-reading of the manuscript. Notably, I should like to express my gratitude to Deutsche Wildtier Stiftung - whose research prize funds my work on human-wildlife coexistence - for allowing me to stray from my main project in order to investigate the conceptual underpinnings of human-animal relations.

\section{References}

Anderson, E. (2004). Animal rights and the values of nonhuman life. In C. R. Sunstein \& M. Nussbaum (Eds.), Oxford: Oxford University Press. Animal rights: current debates and new directions, 277-298.

Bartal, I. B. A., Decety, J., \& Mason, P. (2011). Empathy and pro-social behavior in rats. science, 334(6061), 14271430. http://dx.doi.org/10.1126/science.1210789

Bekoff, M. (2007). The emotional lives of animals: A leading scientist explores animal joy, sorrow, and empathy-and why they matter. Novato: New world library.

Bentley-Condit, V. K., \& Smith, E. (2010). Animal tool use: current definitions and an updated comprehensive catalog. Behaviour, 147(2), 185-132A. http://dx.doi.org/10.1163/000579509X12512865686555

Berry, T. (1999). The Great Work: Our way into the future. New York: Bell Tower.

Boesch, C., \& Tomasello, M. (1998). Chimpanzee and human cultures. Current anthropology, 39(5), 591-614. http://dx.doi.org/10.1086/204785

Brown, C. (2015). Fish intelligence, sentience and ethics. Animal cognition, 18(1), 1-17. http://dx.doi.org/10.1007/s10071-014-0761-0

Carey, S., \& Spelke, E. (1994). Domain-specific knowledge and conceptual change. Mapping the mind: Domain 
specificity in cognition and culture, 169-200. http://dx.doi.org/10.1017/CBO9780511752902.008

Chan, K. (2011). Ethical extensionism under uncertainty of sentience: duties to non-human organisms without drawing a line. Environmental Values, 20(3), 323-346. http://dx.doi.org/10.3197/096327111X13077055165983

Clark, A., \& Chalmers, D. (1998). The extended mind. analysis, 58(1), 7-19. http://dx.doi.org/10.1093/analys/58.1.7

Connor, R., \& Mann, J. (2006). Social cognition in the wild: Machiavellian dolphins? In S. Hurley \& M. Nudds (Eds.) New York: Oxford University Press., Rational animals,329-367. http://dx.doi.org/10.1093/acprof:oso/9780198528272.003.0016

Dally, J. M., Emery, N. J., \& Clayton, N. S. (2010). Avian Theory of Mind and counter espionage by food-caching western scrub-jays (Aphelocoma californica). European Journal of Developmental Psychology, 7(1), 17-37. http://dx.doi.org/10.1080/17405620802571711

Fodor, J. A. (1983). The modularity of mind: An essay on faculty psychology. Cambridge MA: MIT press.

Gabora, L. (2007). Mind In R. A. Bentley, H. D. G. Maschner \& C. Chippendale (Eds.), Handbook of Theories and Methods in Archaeology (pp. 283-296). Walnut Creek CA: Altamira Press.

Gallistel, C. R. (2000). The replacement of general-purpose learning models with adaptively specialized learning modules. The new cognitive neurosciences, 1179-1191.

Gentner, A. M. (2016). Die Typen aus dem Tierreich. GEO, 2, 44-61.

Gentner, D. (1988). Metaphor as structure mapping: The relational shift. Child development, 47-59. http://dx.doi.org/10.2307/1130388

Gruen, L. (2010). The Moral Status of Animals. In E. N. Zalta (Ed.), The Stanford Encyclopedia of Philosophy, (Fall 2014 ed.).

Harnad, S. (2016). Animal Sentience: The other minds problem. Animal Sentience(1).

Husserl, E. (2012). Die Krisis der europäischen Wissenschaften und die transzendentale Phänomenologie. Hamburg: Felix Meiner Verlag.

Janik, V. M., Sayigh, L. S., \& Wells, R. (2006). Signature whistle shape conveys identity information to bottlenose dolphins. Proceedings of the National Academy of Sciences, 103(21), 8293-8297. http://dx.doi.org/10.1073/pnas.0509918103

Jürgens, U. M. (2014). Compassionate Coexistence: Personizing the Land in Aldo Leopold's Land-Ethic. Journal of Evolution and Technology, 24(3).

Jürgens, U. M. (2016). Begegnungen. Tierärztliche Umschau, 224-229.

Jürgens, U.M. (under review). How transspecific encounters are realized: From Respective Realism to Merging Minds.Karmiloff-Smith, A. (1994). Précis of beyond modularity: A developmental perspective on cognitive science. Behavioral and Brain Sciences, 17(04), 693-707.

Mausfeld, R. (2005). Vom Sinn in den Sinnen. Wie kann ein biologisches System Bedeutung generieren? In E. Norbert \& L. Gerd (Eds.), ... sind eben alles Menschen - Verhalten zwischen Zwang, Freiheit und Verantwortung (pp. 4779). Göttingen: Wallstein.

Mausfeld, R. (2008). Intrinsic multiperspectivity: On the architectural foundations of a distinctive mental capacity. In P. A. Frensch \& R. Schwarzer (Eds.), Cognition and Neuropsychology: International Perspectives on Psychological Science (Vol. 1). Oxford: Psychology Press.

Mausfeld, R. (2010). The perception of material qualities and the internal semantics of the perceptual system. In L. Albertazzi, G. van Tonder \& D. Vishwanath (Eds.) Cambridge, MA: MIT Press., Perception beyond Inference. The Information Content of Visual Processes,159-200.

Mishkin, M., Ungerleider, L. G., \& Macko, K. A. (1983). Object vision and spatial vision: two cortical pathways. Trends in neurosciences, 6, 414-417. http://dx.doi.org/10.1016/0166-2236(83)90190-X

Mithen, S. J. (1996). The Prehistory of the Mind a Search for the Origins of Art, Religion and Science. London: Phoenix.

Nagel, T. (1974). What Is It Like to $\mathrm{Be}$ a Bat? The Philosophical Review, 83(4), 435-450. http://dx.doi.org/10.2307/2183914

Nagel, T. (2012). Mind and cosmos: why the materialist neo-Darwinian conception of nature is almost certainly false. New York: Oxford University Press. http://dx.doi.org/10.1093/acprof:oso/9780199919758.001.0001 
Ogden, L. E. (2012). Do Animals Have Personality? BioScience, 62(6), $533-537$. http://dx.doi.org/10.1525/bio.2012.62.6.4

Penn, D. C., \& Povinelli, D. J. (2007). On the lack of evidence that non-human animals possess anything remotely resembling a 'theory of mind'. Philosophical Transactions of the Royal Society of London B: Biological Sciences, 362(1480), 731-744. http://dx.doi.org/10.1098/rstb.2006.2023

Premack, D., \& Woodruff, G. (1978). Does the chimpanzee have a theory of mind? Behavioral and Brain Sciences, 1(04), 515-526. http://dx.doi.org/10.1017/S0140525X00076512

Robbins, P. (2010). Modularity of mind. In E. N. Zalta (Ed.), The Stanford Encyclopedia of Philosophy (Summer 2015 Edition ed.).

Samuels, R. (2000). Massively modular minds: Evolutionary psychology and cognitive architecture. In P. Carruthers \& A. Chamberlain (Eds.) Cambridge: Cambridge University Press., Evolution and the human mind: Modularity, language and meta-cognition, 13-46. http://dx.doi.org/10.1017/CBO9780511611926.003

Shettleworth, S. J. (2001). Animal cognition and animal behaviour. Animal behaviour, 61(2), $277-286$. http://dx.doi.org/10.1006/anbe.2000.1606

Shettleworth, S. J. (2009). Cognition, evolution, and behavior: Oxford University Press.

Shettleworth, S. J. (2012). Modularity, comparative cognition and human uniqueness. Philosophical Transactions of the Royal Society of London B: Biological Sciences, 367(1603), 2794-2802. http://dx.doi.org/10.1098/rstb.2012.0211

Spelke, E. S., \& Lee, S. A. (2012). Core systems of geometry in animal minds. Philosophical Transactions of the Royal Society of London B: Biological Sciences, 367(1603), 2784-2793. http://dx.doi.org/10.1098/rstb.2012.0210

Sperber, D. (1994). The modularity of thought and the epidemiology of representations. In L. A. Hirschfeld \& S. A. Gelman (Eds.) Cambridge: Cambridge University Press., Mapping the mind: Domain specificity in cognition and culture ,39-67. http://dx.doi.org/10.1017/CBO9780511752902.003

Stucki, S. (2015). Die 'tierliche Person' als tertium datur - Eine Extrapolation aus aktuellen tierschutzrechtlichen Subjektivierungsansätzen und kritische Reflexion aus feministischer Perspektive. In C. Amann, B. Christensen, L. Engi \& M. Michel (Eds.), Die Würde der Kreatur - Ethische und Rechtliche Beiträge zu einem umstrittenen Konzept , 287-326.

Tattersall, I. (1998). Becoming Human: Evolution and Human Uniqueness. New York, San Diego, London: Hartcourt Brace \& Company.

von Uexküll, J. (1909). Umwelt und Innenwelt der Tiere. Berlin: Verlag Julius Springer.

Wilson, R. A. (2008). The drink you have when you're not having a drink. Mind \& Language, $23(3), 273-283$. http://dx.doi.org/10.1111/j.1468-0017.2008.00343.x

\section{$(\mathrm{cc}) \mathrm{BY}$}

This work is licensed under a Creative Commons Attribution 3.0 License. 